\title{
Personality and Older Consumers' Green Behaviour in the UK
}

\begin{abstract}
The UK government has set an ambitious target of reducing greenhouse gas emissions by $80 \%$ before 2050. An interesting segment that could help to achieve this is older consumers, due to their growing numbers. There seems a lack of attention, in the research looking specifically at different age categories of older consumers' green behaviour, and whether their level of greenness can be explained by their personality. Using Socioemotional Selectivity Theory and Time Perspective, the research presented here was designed to provide an exploratory analysis of how the green behaviour of older consumers is explained by their personality types. Based on the responses of 204 older consumers in the UK, our results find the openness personality trait to be positively linked to green behaviour, whilst the extraversion personality trait is negatively related to green behaviour. Although the level of green behaviour increased with older consumers' age, this did not reach significance.
\end{abstract}

Keywords: Green Behaviour, Ecologically Conscious Consumption Behaviour, Older Consumers, Socioemotional Selectivity Theory, Time Perspective, Personality Traits 


\section{Personality and Older Consumers' Green Behaviour in the UK}

\subsection{Introduction}

Individuals are becoming increasingly knowledgeable about the environment due to media coverage of environmental protection, environmental deterioration and climate change (do Paço \& Reis, 2012). Therefore, protecting the environment has gained significant importance amongst different countries, marketers and consumers (Cavanaugh, 2011). The UK is one country demonstrating this trend with $94 \%$ of citizens considering that protecting the environment is of importance (European Commission, 2011). Additionally, the UK government aims to reduce the country's greenhouse gas emissions by $80 \%$ before 2050 by adopting different strategies such as investing in low carbon energy innovation, increasing and accelerating the use of renewable energy and investing in nuclear power stations that generate electricity (Department of Energy \& Climate Change, 2012).

Different types of behaviour can be adopted to protect the environment, such as purchasing green products, recycling, disposing of household rubbish in a responsible way and voting for Green political parties. Most green behaviours involve time, money and/or physical and mental effort, which may act as a deterrent to individuals with positive attitudes toward the environment. For example, buying green products is perceived to be more expensive, whilst recycling is thought to take up more time than other options (Stanley \& Lasonde, 1996). Individuals find it impossible to judge the impact their actions have on the environment (French, 2010). This partly explains why some adopt many green behaviours, some choose several or just one, and others do nothing at all (Stanley \& Lasonde, 1996).

Even though consumers may have good environmental intentions, this does not always translate into behaving or even consuming in an environmentally friendly way, the discrepancy being known as the 'attitude-behaviour gap'. According to Riley et al. (2012), this gap is observed in various countries and amongst different demographics (Auger et al., 2003; Chatzidakis et al., 2007; Eckhardt et al., 2010; Schröder \& McEachern, 2005; Szmigin, et al., 2008). This partly explains why the European Commission's (2011) research into 'Attitudes towards the environment' found that, although $91 \%$ of British people agreed that they could individually help to protect the environment, only $74 \%$ were prepared to buy green products. The UK is an interesting market for this research because, according to Longhi (2013), UK citizens will have to significantly change their green behaviour if the government's target for reducing greenhouse gas emissions is to be achieved. An interesting segment within the UK is older consumers, due to their growing numbers (Sudbury \& Simcock, 2010). Less is known about their consumer behaviour compared to other important segments (Williams et al., 2010; Yoon et al., 2005).

This article will address the following questions: Are some age groups of older UK consumers greener than others? Can older consumers' personality explain their level of greenness in the UK? The research presented here was designed to bridge these current gaps in the research by using Socioemotional Selectivity Theory (SST) and Time Perspective (TP). SST explains the differences that age makes to people's behaviour, along with how individuals choose between two kinds of goals: emotion-related and knowledge-related goals. TP concerns how individuals' perceptions of time affect how they select and seek goals, which influences their emotion, cognition and motivations (Carstensen et al., 1999). Older 
adults perceive themselves as having less time to live in comparison to younger adults, so they are more likely to prioritise emotionally meaningful goals than younger adults (Drolet et al., 2010), which may influence their adoption of green behaviour. The remainder of this article is structured as follows. Firstly, it explains the context of the study and why we think personality traits should be able to explain the green behaviour of older consumers. Next, we describe our research methodology, data collection process, and data analysis using regression. Finally, we discuss managerial implications, limitations and future research directions. By providing an understanding of older UK consumers' green behaviour, this article will help to inform the UK government, the media, and manufacturing industries as to whether this is a segment that needs to be targeted or educated on this topic. By looking specifically at their personality traits, this research will enable older consumers to be better targeted by these groups in terms of their green behaviour.

\subsection{Older adults}

According to Riley et al. (2012), older adults are those aged 50 years and above, which is the consensus among gerontologists (e.g. the English Longitudinal Study of Ageing), charities (e.g. Age UK), academics (Carrigan, 1998; Simcock, Sudbury, \& Wright, 2006) and practitioners (e.g. Silversurfers, Saga). This is an interesting group for this research to examine because their importance is illustrated by the relative size of this segment. There are over 21 million people aged 50 years or older in the UK, which is a third of the total UK population. Additionally, there are now more people in the UK aged 60 and above than those aged under 18 (Age UK London, 2011). Although there are a few studies addressing the ethical purchasing behaviour of older consumers (such as Carrigan et al., 2004; Riley et al., 2012), very few articles can be found specifically addressing the green behaviour of older consumers in the UK. The few that exist have found that older adults adopt the greenest behaviour (e.g. Gilg et al., 2005; Longhi, 2013). For example, Sandahl and Robertson (1989) and Sudbury and Simcock (2010) found that older consumers were more environmentally concerned than younger consumers. More recently, Lynn and Longhi's (2011) found that older consumers aged 50 and upwards were more likely to report environmental behaviours than younger consumers on $55 \%$ of the items that they measured, including behaviours such as never leaving the television on standby, always switching off lights, never keeping the tap running, buying recycled paper products, taking their own shopping bags with them, and considering themselves as green in most things or in everything.

A limitation of the prior research is that, although older consumers are not homogeneous, they have been grouped together as one segment. This is supported by Silvers (1997), who found that the lives of people in their 50s are in a constant state of flux, and actually change more than those of people in their 20s. Additionally, Sudbury and Simcock (2009) asserted that treating the over 50s as one segment may result in crucial findings being overlooked within this important segment (Greco, 1986) because older consumers become more dissimilar in terms of lifestyles, needs and consumption habits as they age (Moschis, 1996) due to the different life-changing events they experience, such as the death of a partner or a divorce, along with differences in how they age physiologically, socially and psychologically (Moschis, 2003).

Age segmentation for older consumers is used in the Office for National Statistics' Family Spending report for the UK (ONS, 2013), and in the income section of Age UK's Golden 
Economy Report (2010). There are three different categories for the aged 50 and above, namely those (1) aged 50-64 years, (2) aged 65-74 years, and (3) aged 75 and over. This segmentation is fairly similar to that used in Help the Aged (1999). In that work, the youngest category of older consumers are referred to as 'young old' (aged 55-64) and are among the most socially important of any age group. Additionally, they have high levels of income, savings and expenditure, and are politically active. The oldest category of older consumers are referred to as 'old older' (aged 75+), and mostly comprise women who live alone. They are among the most economically and socially vulnerable of all in society due to having the highest occurrence of poor health and physical immobility. 'Mature olds' (aged 65-74) are found to be in transition between the two stages (Help the Aged, 1999). More recent studies (e.g. ONS, Age UK) have developed the Help the Aged segmentation by lowering the minimum age of the young old segment to include consumers aged from 50, rather than 55. It is important to acknowledge this change because segments of older consumers are 'snapshots in time', which 'change as people change' (Sudbury \& Simcock, 2009, p. 252).

\subsection{Hypotheses Formulation}

\subsection{SST and TP}

This paper uses SST and TP to explain older consumers' green behaviour. SST is when individuals naturally judge their time as being either limited, so that their ending is perceived, or as being expansive, so that their future is perceived as being open-ended (Carstensen, 1992). TP influences their motivation, cognition and emotion, and therefore how they behave in relation to their specific goals. Individuals who think that they have limited time in the world are more present orientated, which makes them choose to enjoy both enjoyable and positive experiences (Carstensen et al., 1999). They place more importance on emotionally meaningful goals that are more immediately rewarding. These goals are related to feelings such as balancing emotional states or sensing that one is needed by others (Fung \& Carstensen, 2003). Their social interactions tend to be limited to those with whom they are more familiar and whom they care about, because these experiences are both predictable and more likely to be positive and meaningful (Carstensen \& Charles, 1998). When they do form new relationships, they tend to be based on emotional compatibility instead of their potential for future contact or for providing new information (Carstensen et al., 1999).

The contrary holds for those who think that time is expansive. They tend to be more future orientated, which makes them pay more attention to planning, being analytical, and pursuing knowledge for their future (Williams \& Drolet, 2005). They plan for what they can experience and enjoy at a later time; this means that their goals tend to be more knowledge related, which can help the individual prepare for their future by saving any newly acquired information for when they might need it (Fung \& Carstensen, 2003). This also influences how they tend to form new social relationships as the latter are based on their capacity to help the individual acquire new information (Drolet et al., 2010).

As individuals' lives become more limited in time, they tend to pursue more emotion-related goals, while being repelled from pursuing knowledge-related goals. The opposite is true for individuals who view their time as expansive, as they tend to be drawn towards knowledgerelated goals and away from emotion-related goals (Drolet et al., 2010). Previous research has found empirical support for these different TPs. For example, Fung and Carstensen (2003) show that consumers with a limited time horizon both prefer, and have higher recall of, 
advertisements with emotion-related rather than knowledge-related appeal. Additionally, Williams and Drolet's (2005) findings that the time horizon moderates responses to both emotional and rational advertisements support this.

Although the monitoring of time in SST is an unconscious, continuous and regular process (Drolet et al., 2010), individuals' perceptions of time horizons can be influenced by life situations, such as illness, frustration, or economic conditions (Carstensen \& Fredrickson, 1998; Fung et al., 1999), or actual changes in one's life expectancy (Fung et al., 2001, as cited in Kuppelwieser \& Sarstedt, 2014). Older consumers may perceive their time as running out due to being closer to the end of their lives. Therefore, they tend to perceive their time horizon as being limited by default, in comparison to younger adults who will view their time as expansive, giving them a tendency to be more future-orientated (Fung et al., 1999). Marketers have the ability to manipulate consumers' TPs through advertising. Consumer research has also adopted this approach of altering individuals' time horizon perspectives (e.g. Fung \& Carstensen, 2003; Williams \& Drolet, 2005, as cited in Kuppelwieser \& Sarstedt, 2014).

\subsubsection{SST, TP and green behaviour}

Research in SST has found strong support for an impact of age amongst older consumers. Carstensen et al. (1999) found that individuals aged 70-83 recalled more emotional information from social narratives than those aged 53-67. Williams and Drolet (2005) found that consumers aged over 65 years preferred, and had higher recall of, emotional appeals in advertisements. Additionally, Jahn et al., (2012) found that consumers aged above 65 years showed stronger emotional brand attachments than those aged between 50 and 65. Looking specifically at the behaviour of older consumers, Lambert-Pandraud et al. (2005) research into the repeat buying of new cars found that older consumers (aged 60 years and over) considered fewer brands, fewer dealers and fewer models and were more likely to repurchase their previous brands. These findings show that older consumers show stronger emotional aspects as they increase in age and their future time horizons become more limited. Williams and Drolet (2005) explain that older adults are more emotionally focused for various reasons, including having a decline in working memory capacity (Hasher \& Zacks, 1988), placing more emphasis on personal values and experiences (Labouvie-Vief and Blanchard-Fields, 1982), developing a more complex understanding of emotions, and being more able to integrate emotions and cognitions as they mature (Labouvie-Vief, 1998).

Previous research has found that older adults tend to adopt greener behaviour than younger adults (e.g. Gilg et al., 2005; Longhi, 2013; Lynn \& Longhi, 2011; Sandahl \& Robertson, 1989; Sudbury \& Simcock, 2010). Milfont et al. (2012) found that future-orientated individuals are more likely to adopt green behaviour than present-orientated individuals. This is supported by Corral-Verdugo et al. (2006), who found a positive correlation between future orientation and water conservation, Carmi (2013), who found that future-orientated individuals behave more responsibly with their use of energy and water when there is a benefit, and Joireman et al. (2004), who found that future-orientated individuals prefer to commute using public transport. When relating the findings of SST to those regarding the adoption of green behaviour, young old consumers are at an earlier stage of the ageing process and perceive themselves as having more time remaining, so they should be more future-orientated than the older age categories. We would therefore expect a difference in the 
adoption of green behaviour across the different age categories of older consumers, with the young olds adopting the strongest behaviour due to being more future-orientated. Due to the remaining age categories perceiving their future as being increasingly limited as they increase in age, we would expect this to decrease their adoption of green behaviour. Therefore, we expect to find that older old consumers (old older) adopt the least green behaviour. Furthermore, life circumstances are very different for older consumers who are still working years than for older consumers who have retired and are living off a pension. This is supported by Help The Aged (1999) finding that young olds have the highest levels of income, savings and expenditure than the other older consumer segments, along with being more physically and mentally fit (Help The Aged, 1999). Therefore, the money and/or physical and mental effort that Stanley \& Lasonde (1996) found to be associated with the adoption of green behaviour would be less of an obstacle for young old consumers. Consistent with these findings, this article hypothesises that:

H1: Young old consumers (aged 50-64 years) exhibit the greenest behaviour, followed by mature old consumers (aged 65-74) and old older consumers (aged 75+) respectively.

\subsection{Personality traits}

'The Big-Five' framework has become the most widely used model in research into personality (Gosling, Rentfrow, \& Swann Jr, 2003). It shows that most personality differences can be represented by five dimensions: (1) neuroticism, which identifies individuals prone to psychological distress, unrealistic ideas, excessive cravings or urges, and maladaptive coping responses; (2) extroversion, which assesses the quantity and intensity of interpersonal interaction, activity levels, the need for stimulation, and the capacity for joy; (3) openness, which assesses the proactive seeking and appreciation of experience for its own sake, and the toleration for and exploration of the unfamiliar; (4) agreeableness, which assesses the quality of an individual's interpersonal orientation along a continuum from compassion to antagonism, in their thoughts, feelings and actions; and (5) conscientiousness, which assesses the individual's degree of organisation, persistence and motivation in goaldirected behaviour (McCrae \& Costa, 1990).

Research has found that individuals' personality traits are related to different types of human behaviour in different situations, including gambling behaviour (Blaszczynski et al., 1999), blood donation behaviour (Paunonen \& Nicol, 2001), housing behaviour (Sweaney et al., 1984), leadership behaviour (Judge \& Bono, 2000), and music-listening preferences (Rentfrow \& Gosling, 2003, as cited in Landers \& Lounsbury, 2006). Specifically within the area of consumer research, Goldsmith (2002) found that regular clothes purchasers have distinct personality traits from those who purchase infrequently, whilst other studies have linked the Big Five to brand personality (e.g. Mulyanegara et al., 2009; Tsu Wee, 2004).

\subsubsection{Personality traits and green behaviour}

Only a few articles on green issues, to date, have linked green behaviour with personality, which is surprising as it would, for example, benefit marketers to know whether certain personality traits influenced green behaviour. Balderjahn (1988) found personality to have an effect on green consumption and usage, Ramanaiah, Clump, and Sharpe (2000) found differences in personality traits between individuals scoring high and low in terms of 
environmental responsibility, whilst Fraj and Martinez (2006) found that individuals with different personality traits responded differently to green actions.

More specifically in terms of personality traits, research shows that highly open individuals, who are curious, creative, imaginative and untraditional (McCrae \& Costa, 1990), are positively related to green behaviours and attitudes. For example, Markowitz, Goldberg, Ashton, \& Lee's (2012) research into personality traits and pro-environmental (green) behaviour found that the openness personality trait was strongly related to older individuals with a mean age of 51.3 years. Further support for the relationship of the openness personality trait with green behaviour was also found in Hirsh and Dolderman's (2007) research into personality, consumer goals and environmental attitudes, which showed a positive link. Soliño and Farizo's (2014) research into how personality traits relate to green preferences found that highly open individuals were the most likely to choose options aimed at environmental protection compared to other personality traits. Additionally, both the openness and extraversion personality traits were found to positively affect consumers' preferences for environmental programmes. A highly extroverted individual is sociable, active, person-orientated and talkative (McCrae \& Costa, 1990), and Fraj and Martinez' (2006) research into personality and ecological (green) behaviour found that the extraversion trait would have a positive influence on the latter. However, no consistent support has been found in the literature for a link between any of conscientiousness, neuroticism and agreeableness, and green behaviour. A highly conscientious individual is punctual, reliable, ambitious, organised and neat; a highly neurotic individual worries, and is nervous and insecure; and a highly agreeable individual is helpful, soft-hearted and good-natured (McCrae \& Costa, 1990). Consistent with these prior findings, we hypothesise that:

H2: Older consumers exhibiting open and extroverted personality traits adopt the greenest behaviour.

\subsection{Methodology}

We used the Ecologically Conscious Consumption Behaviour (ECCB) scale (Roberts, 1996) to measure the green behaviour of the respondents. Previous articles have used this to measure green behaviour (e.g. Akehurst et al., 2012; Roberts, 1996; Straughan \& Roberts, 1999) because it has the advantage of overcoming the attitude-behaviour gap by measuring people's declarations of what they do (Straughan \& Roberts, 1999). Originally, this scale was based on exploratory factor analysis and consisted of 30 items capturing a wide variety of ecologically conscious consumption behaviours. We reduced this list to 22 items by deleting those involving money-saving behaviour. Even at 22 items, the scale was quite long, with repetition. We content-analysed all the ECCB items (Roberts, 1996) to remove redundant and domain-irrelevant items. We deleted those items that primarily reflected (a) product-specific ECCB or (b) any ECCB that might, again, relate to money-saving behaviour. Finally, 10 items remained that were directly relevant indicators of ECCB. The items were anchored on a scale of 1 to 5 with 1 meaning 'never true' and 5 meaning 'always true'. To measure the personality traits of the respondents, we used Gosling et al.'s (2003) short scale of the Big Five personality domains. Respondents were asked to rate their agreement with the scale items on 1 to 5 with 1 meaning 'strongly disagree' and 5 meaning 'strongly agree'. 
We were concerned about method bias including social desirability bias affecting true relationships between the substantive constructs (Ganster et al., 1983). To control for method bias, a serious concern for researchers (Podsakoff et al., 2003), we embedded two marker variables in the questionnaire (Lindell \& Whitney, 2001; Williams et al., 2010). Marker variable technique is a partial correlational technique for estimating and controlling the method bias within a study (cf. Lindell \& Whitney, 2001; Podsakoff et al., 2003; Williams et al., 2010). One marker variable was positively worded and measured the respondents' perceptions of the safety of their neighbourhood on a scale of 1 to 5 with 1 meaning 'very unsafe' and 5 meaning 'very safe'; the other marker variable was negatively worded and measured their attitudes towards exercise on a scale of 1 to 5 with 1 meaning 'strongly disagree' and 5 meaning 'strongly agree'. Neither had any theoretical correlation with the focal constructs of the study (Lindell \& Whitney, 2001; Richardson et al., 2009). The negatively worded marker variable was expected to capture common method bias and the positively worded marker variable was expected to capture acquiescence bias. We promised respondent anonymity and confidentiality of their data to alleviate the tendency to provide socially desirable responses (Heneman, 1974; Podsakoff et al., 2003). The survey instrument had equal numbers of positively and negatively worded items to reduce potential method bias. The self-report, closed-ended survey instrument was piloted on seven older consumers. Based on their feedback, we decided to ask for their age category, namely, (1) 'young old' aged 50 to 64 years, (2) 'mature old' aged 65 to 74 years, or (3) 'old older' aged 75 years and above, rather than their precise age, because this was considered less intrusive for our target audience.

We found it difficult to recruit older participants for our research, and they were very suspicious about participating in consumer-related research. We sought help with the data collection from the University of Portsmouth Aging Network (UPAN), which connected us with various local older persons' organisations. These organisations meet regularly to discuss local issues and items of interest. Their members consist of independent and able-bodied older consumers. The data were collected in person at group meetings following a brief introduction to the research that did not reveal the focal constructs of the study. We also highlighted that contributing to the research was not compulsory and we only administered surveys to the members who wanted to participate. After deleting any surveys that were largely incomplete, we were left with 204 usable completed surveys from older consumers. Of these, $55 \%$ belonged to the young old group, $31 \%$ to the mature old group and $14 \%$ to the old older group. Since females tend to live longer than men (ONS, 2014), it is not surprising that $74 \%$ of the respondents were female and $25 \%$ were male.

\subsection{Analysis and results}

Data exploration revealed that all but one item had kurtosis and skewness greater than \pm 1.96 . Table 1 presents Pearson correlations, partial correlations, means and standard deviations. The table shows that the first marker variable M1, capturing common method bias, and the second marker variable M2, capturing acquiescence bias, are not significantly correlated with the focal constructs, except in the case of the agreeableness personality dimension which is significantly correlated $(p<.05)$ with M2.

Insert Table 1 about here 
We put the ECCB scale through confirmatory factor analysis (Anderson \& Gerbing, 1988) to check whether the items actually reflected the underlying latent construct. We used IBM SPSS AMOS 21.0 software for running the confirmatory factor analysis. The ECCB yielded an adequate fit ( $\mathrm{Hu} \&$ Bentler, 1999) with the data $(\chi 2=85.7, \mathrm{df}=35, \mathrm{CFI}=.96, p<.01$, $\mathrm{TLI}=.93, \mathrm{RMSEA}=.084$, construct reliability $=.89$, average variance extracted $=.54)$. The scale items and their factor loadings are given in Table 2. The construct reliability was over .7 and the average variance extracted (AVE) was greater than .5 (Fornell \& Larcker, 1981). All the item loadings were more than .5 , suggesting convergent validity of the scale. The Big Five personality factors were excluded from the confirmatory factor analysis because running such an analysis on them would not have been possible as they were under-identified models.

Insert Table 2 about here

To test the hypotheses, we ran hierarchical regressions using IBM SPSS Version 20. The results from the data analysis are presented in Table 3. Model 1 presents the results of a full regression with all the explanatory factors entered simultaneously. The overall model is statistically significant, explaining $11 \%$ of the variance in green behaviour $\left(\mathrm{R}^{2}=.11\right)$. Our analysis finds two significant effects supporting our hypotheses. The extraversion personality trait shows a negative relationship with green behaviour, whilst the openness personality trait shows a positive one. Model 2 incorporates the method bias and acquiescence bias marker variables in the analysis to correct the effect estimates for any potential common method bias effects. The results show that common method bias does not seem to have influenced our data or our findings. The bias-corrected significant estimates are only marginally different from the original estimates of Model 1. It seems that the extraversion $\rightarrow$ ECCB relationship was marginally inflated due to method bias (original $\beta-.145$, bias corrected $\beta-.142$ ) and the openness $\rightarrow$ ECCB relationship was marginally underestimated due to method bias (original $\beta .300$, bias corrected $\beta$.310).

Insert Table 3 about here

The study fails to find a significant impact of the age of older consumers on their green behaviour. This result is contrary to our expectations. The average green behaviour scores were 3.25 (SD .98) for the young old group, 3.36 (SD .76) for the mature old group and 3.56 (SD .90) for the old older group, with the scale ranging between 1 and 5. We ran a one-way ANOVA to test if the age groups exhibited significantly different green behaviour. The test could not detect significantly different green behaviour across the age groups.

\subsection{Discussion and conclusion}

This study was designed in reference to the UK government's target of reducing greenhouse emissions by $80 \%$ before 2050 . We have explored the green behaviour of the older consumers' segment, important due to its growing numbers. Overall, our study has found that older consumers in the UK are moderately green. Their mean green behaviour was shown to be average (3.32, with a SD of .9 on a scale from 1 to 5, where 1 could be interpreted as adopting very little green behaviour and 5 as adopting a high amount of green behaviour), 
indicating that they do have scope for further improvement. These results indicate to the UK government, industry, marketing practitioners and consumer researchers that there is a need to educate older consumers about adopting greener behaviour.

We find the openness personality trait to be positively related to green behaviour and the extraversion personality type to be negatively related to green behaviour. Our openness finding is consistent with other research (e.g. Hirsh, 2010; Hirsh \& Dolderman, 2007; Markowitz et al., 2012). If consumers are moderately green, it seems reasonable to expect that those who are highly open and thus curious, imaginative and untraditional (McCrae \& Costa, 1990) are more likely to adopt green behaviour because this trait may enhance their experience of nature, which could increase their personal valuation of the natural environment (Hirsh \& Dolderman, 2007). Our extraversion finding is supported by Markowitz et al. (2012), who also found a negative correlation between extraversion and green behaviour amongst older consumers. If consumers are moderately green, it seems reasonable to expect that those who are highly extroverted are distracted from adopting green behaviour due to having other preferences such as being sociable, active, person-orientated and talkative (McCrae \& Costa, 1990). Our result does not support the findings of Fraj and Martinez (2006) or Soliño and Farizo (2014), who found a positive relationship between extraversion and green behaviour/attitudes. However, their samples consisted of all age groups of adults, with only a minority (19\%) being older consumers in the Fraj and Martinez (2006) research, implying that their results may not be valid for older consumers specifically. Additionally, both pieces of research were conducted in Spain rather than in the UK, and green behaviour can be in a constant state of change due to country-specific environmental initiatives and legislation, for example.

Our data does not show a significant difference between the green behaviour of the three categories of old consumers in the UK. However, they do show different means of green behaviour across age groups with the oldest group being the most green followed by matureold consumers and young-old consumers. We followed up our analysis by collecting the green behaviour of 155 young consumers in the UK, who were less than 35 years of age. Their average green behaviour score was the lowest of all the groups (mean 2.99, SD .9). This finding indicates that currently young UK consumers are less green than their elders, which is consistent with previous research (Lynn \& Longhi, 2011; Sandahl \& Robertson, 1989; Sudbury \& Simcock, 2010). One reason could be due to the prevailing societal norms, values and habits of these generations that have shaped their consumption behaviour, which is the case for older consumers, who have still not changed despite their TP becoming more present orientated. The finding raises an important question, 'does socialisation wield greater influence on human behaviour than TP?' Most consumer behaviours are driven by habit due to being performed regularly, which causes them to become both routine and automatic. Habits therefore 'reduce the amount of deliberate thought needed to act...' (Cole et al., 2008, p. 361), with older people being more likely to use and rely on them due to cognitive deficits. By adopting this rationale regarding green behaviour, older UK consumers may not change their level of green behaviour because they are set in their ways after the age of 50 .

Furthermore, the young old category that we have used in this study is very broad. Individuals falling within the ages of 50 and 64 can be either working or retired. This means that their priorities, routines, behaviour and therefore potentially their time horizons and goals 
will differ, potentially affecting their green behaviour. Additionally, the different times at which they were born mean that different events could have influenced their behaviour (period effects) and resulted in generational effects that would not replicate as the next generation ages. For example, the older individuals in this category will have been born just after World War 2, when routine behaviour still consisted of rationing, re-using and saving items. The emphasis would have been very different for the younger young olds born in the 1960s. This demonstrates the limitations of using chronological age when segmenting older individuals to predict their green behaviour. We chose to use chronological age in this study because of the advantages it has over using cognitive age. It is the most commonly used measure when studying aging (Cunningham \& Brookbank, 1988), and when studying consumer behaviour, to segment markets (Barak \& Schiffman, 1981). More specifically, it is a segmentation method that can easily be adopted (Jahn et al., 2012) and it is more closely related to future TP (Carstensen, 1995; Henry, 2000; Padawer et al., 2007 as cited in Jahn et al., 2012). However, it does not fully represent an individual's attitudes or consumer behaviour (Chua et al., 1990; Van Auken, Barry, \& Anderson, 1993). An individual's selfperceived age is an alternative measurement that has been used in research investigating older consumers and values (Kohlbacher \& Chéron, 2010; Sudbury \& Simcock, 2009). Differences of between 8 and 12 years have been reported by older UK consumers between their actual and self-perceived ages (Carrigan \& Szmigin, 2000; Sudbury, 2004). Self-perceived age can be measured using a cognitive scale looking at biological, psychological and sociological dimensions (Riley, 1985). As Sudbury and Simcock (2009, p. 25) remark, 'biological aging is likely to alter consumer needs and the consumer's ability to function in the marketplace; psychological aging has implications for a wide variety of consumer information processing and problem solving abilities (Moschis, 2000); and the social aspects of age and aging are important because society has expectations from people of different ages, as society is age graded (Birren and Cunningham, 1985)'. All of these factors may have an impact on the green behaviour of older consumers.

\subsection{Future research and limitations}

There is still a possibility of improving the explanatory power of the model for the green behaviour of older consumers. There may be other important factors than personality traits and age that explain older consumers' green behaviour. Although demographic variables such as gender and education, along with psychographic variables, have previously been researched in terms of green behaviour, the findings have varied in consistency. We specifically chose our variables because they were under-researched, to contribute to the development of this field.

Individual values may also contribute to explaining older consumers' green behaviour as they have been found to influence people's beliefs (Collins et al., 2007), along with the importance they attach to product and service attributes (Batra et al., 2001). According to Sudbury and Simcock (2009), values are developed from cultural heritage and personal experiences, and differences between generations have been found in various studies (Kahle, Beatty, \& Homer, 1986; Kahle \& Kennedy, 1988). The five values that are rooted in older consumers are autonomy and self-sufficiency, social and spiritual connectedness, altruism, personal growth, and revitalisation (Wolfe, 1994, 1997), and their explanatory power for green behaviour could also be tested. It seems plausible that a more altruistic older individual would be more willing to adopt green behaviour, for example, due to 'compassion for others 
and concern for the world about them' (Wolfe, 1988, p. 50; see also Plutzer \& Berkman, 2005). Future research in this area should explore the role of altruism in explaining green behaviour.

The results of our research should be interpreted keeping the limitations in mind. Firstly, our study is based on subjective self-reports of older consumers in the UK. Future research should use objective data to study green behaviour. Secondly, we did not measure how the individuals' rated their TP, which could have influenced their goal preferences and how they prioritised their adoption of green behaviour. Thirdly, although we tried controlling for method bias by using the marker variable technique, there was still a small chance of social desirability bias influencing our data. Finally, the older consumer groups were located in the south of England, creating a likelihood of geodemographic factors influencing the results. Future research should collect data representing a more even distribution of older UK consumers. 


\section{Acknowledgements}

We would like to thank Portsmouth Business School's Research Project Fund for providing funding for this research. Additionally, we would like to thank Chris Bartley and Alessandro Bellafiore for their contributions to this paper, along with the University of Portsmouth's Ageing Network for helping us contact older consumers. 


\section{References}

Age UK London (2010). The Golden Economy. Retrieved from: http://www.ageuk.org.uk/Documents/EN-GB/For-professionals/Consumerissues/The\%20Golden\%20Consumer\%20October\%202010_pro.pdf?dtrk=true

Age UK London (2011). Key Statistics. Retrieved from:

http://www.ageuk.org.uk/london/about-age-uk-london/media-centre/key-stats/

Akehurst, G., Afonso, C., \& Goncalves, H. M. (2012). Re-examining green purchase behaviour and the green consumer profile: new evidences. Management Decision,50(5), 972988.

Anderson, J. C., \& Gerbing, D. W. (1988). Structural equation modelling in practice: a review and recommended two-step approach. Psychological Bulletin, 1033, 411-423.

Auger, P., Burke, P., Devinney, T. M., \& Louviere, J. J. (2003). What will consumers pay for social product features? Journal of Business Ethics, 42(3), 281-304.

Balderjahn, I. (1988). Personality variables and environmental attitudes as predictors of ecologically responsible consumption patterns. Journal of Business Research, 17(1), 51-56.

Barak, B., \& Schiffman L. G. (1981). Cognitive age: a nonchronological variable. Advances in Consumer Research, 8, 602-606.

Batra, R., Homer, P., \& Kahle, L. (2001). Values, susceptibility to normative influence, and attribute importance weights: A nomological analysis. Journal of Consumer Psychology, 11, $115-128$

Birren, J., \& Cunningham, W. R. (1985). Research on the psychology of aging: principles, concepts and theory. In J. E. Birren \& K. W. Schaie (eds.), Handbook of the Psychology of Aging (2nd ed., pp. 44-593). New York: Van Nostrand Reinhold Company.

Blaszczynski, A., Walker, M., Sagris, A., \& Dickerson, M. (1999). Psychological aspects of gambling behavior: an Australian Psychological Society position paper. Australian Psychologist, 34(1), 4-16.

Carmi, N. (2013). Caring about tomorrow: future orientation, environmental attitudes and behaviors. Environmental Education Research, 19(4), 430-444.

Carrigan, M. (1998). Segmenting the grey market: the case for fifty-plus life groups. Journal of Marketing Practice: Applied Marketing Science, 4(2), 43-56.

Carrigan, M., \& Szmigin, I. (2000). The older consumer as innovator: does cognitive age hold the key? Journal of Marketing Management, 16, 505-527.

Carrigan, M., Szmigin, I., Wright, J. (2004). Shopping for a better world? An interpretive 
study of the potential for ethical consumption within the older market. Journal of Consumer Marketing, 21(6), 401-417.

Carstensen, L. L. (1992). Social and Emotional Patterns in Adulthood: Support for Socioemotional Selectivity Theory. Psychology and Aging, 7(September), 331-338.

Carstensen, L. L. (1995). Evidence for a life-span theory of socioemotional selectivity. Current directions in Psychological Science, 4(5), 151-156.

Carstensen, L. L., \& Charles, S. T. (1998). Emotion in the second half of life. Current Directions in Psychological Science, 7(5), 144-149.

Carstensen, L. L., \& Fredrickson, B. F. (1998). Socioemotional selectivity in healthy older people and younger people living with the human immunodeficiency virus: The centrality of emotion when the future is constrained. Health Psychology, 17(6), 494-503.

Carstensen, L. L., Isaacowitz, D. M., \& Charles, S. T. (1999). Taking time seriously: A theory of socioemotional selectivity. American Psychologist, 54(3), 165-181.

Cavanaugh, L. (2011). Conservation through consumption. Advances in Consumer Research, 39, 194-98.

Chatzidakis, A., Hibbert, S., Smith, A. P. (2007). Why people don't take their concerns about fairtrade to the supermarket: the role of neutralisation. Journal of Business Ethics, 74, 89 -100 .

Chua, C., Cote, J. A., \& Leong, S. M. (1990). The antecedents of cognitive age. Advances in Consumer Research, 17, 880-885.

Cole, C., Laurent, G., Drolet, A., Ebert, J., Gutchess, A., Lambert-Pandraud, R., Mullet, E., Norton, M. I., \& Peters, E. (2008). Decision making and brand choice by older consumers. Marketing Letters, 19(3-4), 355-365.

Collins, C. M., Steg, L., Koning, M. A. S. (2007). Customers' values, beliefs on sustainable corporate performance, and buying behavior. Psychology \& Marketing, 24, 555-577.

Corral-Verdugo, V., Fraijo-Sing, B., \& Pinheiro, J. Q. (2006). Sustainable behavior and time perspective: Present, past, and future orientations and their relationship with water conservation behavior. Interamerican Journal of Psychology, 40(2), 139-147.

Cunningham, W. R., \& Brookbank, J. W. (1988). Gerontology: The Psychology, Biology, and Sociology of Aging. Harper \& Row: London.

Department of Energy \& Climate Change. (2012). Low carbon technologies policy: Actions. Retrieved from https://www.gov.uk/government/policies/increasing-the-use-of-low-carbontechnologies\#actions 
do Paço, A. M. F., \& Reis, R. (2012). Factors affecting skeptism towards green advertising. Journal of Advertising, 41(4), 147-155.

Drolet, A., Lau-Gesk, L., Williams, P., \& Jeung, H. G. (2010). Socioemotional selectivity theory: Implications for consumer research. In A. Drolet, N. Schwarz, \& C. Yoon (Eds.), The aging consumer (pp. 51-72). New York: Routledge.

Eckhardt, G. M., Belk, R., \& Devinney, T. M. (2010). Why don't consumers consume ethically? Journal of Consumer Behaviour, 9(6), 426-436.

European Commission (2011). Eurobarometer surveys on public attitudes to the environment. Retrieved from:

http://ec.europa.eu/environment/pdf/EB_PresentationEB752.pdf

Fornell, C., \& Larcker, D. (1981). Evaluating structural equation models with unobservable variables and measurement error. Journal of Marketing Research, 181, 39-50.

Fraj, E., \& Martinez, E. (2006). Influence of personality on ecological consumer behaviour. Journal of Consumer Behaviour, 5, 167-181.

French, S. (2010). Change is in the air? Talk the green talk, shop the green walk. Advances in Consumer Research, 37, 32-35.

Fung, H. H., Carstensen, L. L., \& Lutz, A. M. (1999). Influence of time on social preferences: implications for life-span development. Psychology and Aging, 14(4), 595-604.

Fung, H. H., Lai, P., \& Ng, R. (2001). Age differences in social preferences among Taiwanese and Mainland Chinese: the role of perceived time. Psychology and aging, 16(2), 351-356.

Fung, H. H., \& Carstensen, L. L. (2003). Sending memorable messages to the old: age differences in preferences and memory for advertisements. Journal of Personality and Social Psychology, 85(1), 163-178.

Ganster, D., Hennessey, H., \& Luthans, F. (1983). Social desirability response effects: Three alternative models. Academy of Management Journal, 26, 321-331.

Gilg, A., Barr, S., \& Ford, N. (2005). Green consumption or sustainable lifestyles? Identifying the sustainable consumer. Futures, 37(6), 481-504.

Goldsmith, R. E. (2002). Explaining and predicting the consumer intention to purchase over the internet: an exploratory study. Journal of Marketing Theory \& Practice, 10(2), 22-28.

Gosling, S. D., Rentfrow, P. J., \& Swann Jr, W. B. (2003). A very brief measure of the Big Five personality domains. Journal of Research in Personality, 37, 504-528.

Greco, A. J. (1986). The fashion-conscious elderly: a viable, but neglected market segment. 
Journal of Consumer Marketing, 3(4), 71-75.

Hasher, L., \& Zacks, R. T. (1988). Working memory, comprehension, and aging: A review and a new view. Psychology of Learning and Motivation, 22, 193-225.

Help the Aged (1999). Grey Power: The Changing Face. London: Help the Aged.

Heneman, H. (1974). Comparisons of self and superior ratings of managerial performance. Journal of Applied Psychology, 59(5), 638-642.

Henry, P. (2000). Modes of thought that vary systematically with both social class and age. Psychology \& Marketing, 17(5), 421-440.

Hirsh, J. B. (2010). Personality and environmental concern. Journal of Environmental Psychology, 30(2), 245-248.

Hirsh, J. B., \& Dolderman, D. (2007). Personality predictors of consumerism and environmentalism: A preliminary study. Personality and Individual Differences, 43(6), 1583 1593.

Hu, L. T, \& Bentler, P. (1999). Cutoff criteria for fit indexes in covariance structure analysis: conventional criteria versus new alternatives. Structural Equation Modelling, 61(1), 55-63.

Jahn, S., Gaus, H., \& Kiessling, T. (2012). Trust, commitment, and older women: exploring brand attachment differences in the elderly segment. Psychology \& Marketing, 29(6), 445457.

Joireman, J. A., Van Lange, P. A., \& Van Vugt, M. (2004). Who cares about the environmental impact of cars? Those with an eye toward the future. Environment and Behavior, 36(2), 187-206.

Judge, T. A., \& Bono, J. E. (2000). Five-factor model of personality and transformational leadership. Journal of Applied Psychology, 85(5), 751-765.

Kahle, L., Beatty, S. E., \& Homer, P. (1986). Alternative measurement approaches to consumer values: The list of values LOV and values and life style VALS. Journal of Consumer Research, 13, 405-409.

Kahle, L., \& Kennedy, P. (1988). Using the list of values LOV to understand consumers. The Journal of Services Marketing, 2, 49-56.

Kohlbacher, F., \& Chéron E. (2010). Segmenting the silver market using cognitive age and the list of values: Empirical evidence from Japan. European Advances in Consumer Research (EACR) Conference, London.

Kuppelwieser, V. G., \& Sarstedt, M. (2014). Applying the future time perspective scale to 
advertising research. International Journal of Advertising, 33(1), 113-136.

Labouvie-Vief, G. (1998). Cognitive-Emotional Integration in Adulthood. In K. Warner Schaie and M. Powell Lawton (Eds.), Annual Review of Gerontology and Geriatrics: Focus on Emotion and Adult Development (vol. 17, pp. 206-237). New York: Springer.

Labouvie-Vief, G., \& Blanchard-Fields, F. (1982). Cognitive ageing and psychological growth. Ageing and Society, 2(2), 183-209.

Lambert-Pandraud, R., Laurent, G., \& Lapersonne, E. (2005). Repeat purchasing of new automobiles by older consumers: empirical evidence and interpretations. Journal of Marketing, 69(2), 97-113.

Landers, R. N., \& Lounsbury, J. W. (2006). An investigation of Big Five and narrow personality traits in relation to internet usage. Computers in Human Behavior, 22(2), 283 $-293$.

Lindell, M. K., \& Whitney, D. J. (2001). Accounting for common method variance in crosssectional research designs. Journal of Applied Psychology, 861, 114-121.

Longhi, S. (2013). Individual pro-environmental behaviour in the household context (No. 2013-21). ISER Working Paper Series.

Lynn, P., \& Longhi, S. (2011). Environmental attitudes and behaviour: who cares about climate change? Colchester: Understanding Society, Institute for Social and Economic Research, University of Essex.

Markowitz, E. M., Goldberg, L. R., Ashton, M. C., \& Lee, K. (2012). Profiling the "pro-environmental individual": A personality perspective. Journal of Personality, 80(1), 81111.

McCrae, R. R., \& Costa, P. T. (1990). Personality in Adulthood. New York: Guildford Press.

Milfont, T. L., Wilson, J., \& Diniz, P. (2012). Time perspective and environmental engagement: A meta-analysis. International Journal of Psychology, 47(5), 325-334.

Moschis, G. P. (1996). Life stages of the mature market. American Demographics, 18(9), 4451 .

Moschis, G. P. (2000). Consumer behavior in later life: multidisciplinary approaches and methodological issues. Research in Consumer Behavior, 9, 103-128.

Moschis, G. P. (2003). Marketing to older adults: an updated overview of present knowledge and practice. Journal of Consumer Marketing, 20(6), 516-525.

Mulyanegara, R. C., Tsarenko, Y., \& Anderson, A. (2009). The Big Five and brand personality: investigating the impact of consumer personality on preferences towards 
particular brand personality. Journal of Brand Management, 16(4), 234-247.

ONS (Office for National Statistics) (2013). Chapter 2 of Family Spending : Housing Expenditure. Retrieved from:

http://www.ons.gov.uk/ons/rel/family-spending/family-spending/2013-edition/rpt-chapter-2-housing-expenditure.html\#tab-Expenditure-by-Age-of-the-Household-Reference-Person

ONS (Office for National Statistics) (2014). National Life Tables. Retrieved from: http://www.ons.gov.uk/ons/rel/lifetables/national-life-tables/2010---2012/stb-uk-20102012.html\#tab-Life-Expectancy-at-Older-Ages

Padawer, E. A., Jacobs-Lawson, J. M., Hershey, D. A., \& Thomas, D. G. (2007). Demographic indicators as predictors of future time perspective. Current Psychology, 26(2), 102-108.

Paunonen, S.V., \& Nichol, A. A. M. (2001). The personality hierarchy and the prediction of work behaviors. In B. W. Roberts and R. Hogan (eds.), Personality Psychology in the workplace (p. 161-191). Washington, DC: American Psychological Association.

Plutzer, E., \& Berkman, M. (2005). The graying of America and support for funding the nation's schools. Public Opinion Quarterly, 69, 66-86.

Podsakoff, P. M., MacKenzie, S. B, Lee, J. Y., \& Podsakoff, N. P. (2003). Common method biases in behavioral research: a critical review of the literature and recommended remedies. Journal of Applied Psychology, 885, 879-903.

Ramanaiah, N. V., Clump, M., \& Sharpe, P. J. (2000). Personality profiles of environmentally responsible groups. Psychological Reports, 87(August), 176-178.

Rentfrow, P. J., \& Gosling, S. D. (2003). The Do Re Mi's of everyday life: the structure and personality correlates of music preferences. Journal of Personality and Social Psychology, 84(6), 1236-1256.

Richardson, H. A., Simmering, M. J., \& Sturman, M. C. (2009). A tale of three perspectives: examining post hoc statistical techniques for detection and correction of common method variance. Organizational Research Methods, 12, 762-800.

Riley, M. W. (1985). Age strata in social systems. In R. H. Binstock and E. Shanas (Eds.), Handbook of Aging and the Social Sciences (pp. 369-411). New York: Van Nostrand Reinhold.

Riley, L. S., Kohlbacher, F.,. \& Hofmeister, A. (2012). A cross-cultural analysis of proEnvironmental consumer behaviour among seniors. Journal of Marketing Management, $28(3$ 4), 290-312.

Roberts, J. A. (1996). Green consumers in the 1990s: profile and implications for advertising. Journal of Business Research, 36(July), 217-231. 
Sandahl, D. M., \& Robertson, R. (1989). Social determinants of environmental concern: specification and test of the model. Environment and Behaviour, 21(1), 57-81.

Schröder, M. J. A., \& McEachern, M. G. (2005). Fast foods and ethical consumer value: a focus on McDonald's and KFC. British Food Journal, 107(4), 212-224.

Silvers, C. (1997). Smashing old stereotypes of 50-plus America. Journal of Consumer Marketing, 14(4), 303-309.

Simcock, P., Sudbury, L., \& Wright, G. (2006). Age, perceived risk and satisfaction in Consumer decision making: a review and extension. Journal of Marketing Management, 22(2-3), 355-378.

Soliño, M., \& Farizo, B. A. (2014). Personal Traits Underlying Environmental Preferences: A Discrete Choice Experiment. PLOS ONE, 9(2), e89603.

Stanley, L. R., \& Lasonde, K. M. (1996). The relationship between environmental issue involvement and environmentally conscious behavior: an exploratory study. Advances in Consumer Research, 23(1), 183-188.

Straughan, R. D., \& Roberts, J. A. (1999). Environmental segmentation alternatives: a look at green consumer behaviour in the new millennium. Journal of Consumer Marketing, 166, 558-575.

Sudbury, L. (2004). Subjective age perceptions in the UK: an empirical study. Quality in Ageing - Policy, Practice and Research, 5(1), 4-13.

Sudbury, L., \& Simcock, P. (2009). A multivariate segmentation model of senior consumers. Journal of Consumer Marketing, 26(4), 251-262.

Sudbury, L., \& Simcock, P. (2010). Using qualitative diary research to analyse older consumers' packaging experiences. Paper presented at the American Marketing Association Summer Marketing Educators Conference: Boston, MA.

Sweaney, A. L., Pittman, J. F., \& Montgomery, J. E. (1984). The influence of marital status and age on the housing behavior of older southern women. Journal of Housing for the Elderly 2(3), 25-36.

Szmigin, I., Carrigan, M., \& McEachern, M. G. (2008). Flexibility, dissonance and the conscious consumer. European Advances in Consumer Research, 8(July), 379-380.

Tsu Wee, T. T. (2004). Extending human personality to brands: the stability factor. Brand Management, 11(4), 317-330.

Van Auken, S., Barry, T. E., \& Anderson, R. L. (1993). Towards the internal validation of cognitive measures in advertising research. Journal of Advertising Research, 33(3), 82-84. 
Williams, P., \& Drolet, A. (2005). Age-Related Differences in Responses to Emotional Advertisements. Journal of Consumer Research, 32(3), 343-354.

Williams, L., Hartman, N., \& Cavazotte, F. (2010). Method variance and marker variables: a review and comprehensive CFA marker technique. Organizational Research Methods, 13(3), 477-514.

Wolfe, D. B. (1988). Learning to speak the language of the new senior. Marketing Communications, 13, 47-52.

Wolfe, D. B. (1994). Targeting the mature mind. American Demographics, 16, 32-36.

Wolfe, D. B. (1997). Older markets and the new marketing paradigm. Journal of Consumer Marketing, 14, 294-302.

Yoon, C., Laurent, G., Fung, H. H., Gonzales, R., Gutchess, A. H., Hedden, T., LambertPandraud, R., Mather, M., Park, D. C., Peters, E., \& Skurnik, I. (2005). Cognition, persuasion and decision making in older consumers. Marketing Letters, 16(3), 429-441. 
Table 1 Correlations and descriptive statistics

\begin{tabular}{|c|c|c|c|c|c|c|c|c|}
\hline Construct & ECCB & Extra & Agree & Cons & ES & $\mathrm{OE}$ & M1 & M2 \\
\hline ECCB & $\begin{array}{l}3.32 \\
(.90)\end{array}$ & & & & & & & \\
\hline Extra & -.05 & $\begin{array}{c}3.26 \\
(1.04)\end{array}$ & & & & & & \\
\hline Agree & -.09 & .07 & $\begin{array}{l}4.10 \\
(.69)\end{array}$ & & & & & \\
\hline Cons & .11 & .12 & $.27 * *$ & $\begin{array}{l}4.14 \\
(.76)\end{array}$ & & & & \\
\hline $\mathrm{ES}$ & -.03 & .08 & $.32 * *$ & $.36^{* *}$ & $\begin{array}{l}3.80 \\
(.88)\end{array}$ & & & \\
\hline $\mathrm{OE}$ & $.29 * *$ & $.38 * *$ & .02 & $.22 * *$ & $.21 * *$ & $\begin{array}{l}3.93 \\
(.77)\end{array}$ & & \\
\hline Marker1 & .05 & -.01 & -.07 & .07 & .04 & -.11 & $\begin{array}{l}3.96 \\
(.77)\end{array}$ & \\
\hline Marker2 & .09 & -.09 & $-.18 *$ & -.06 & .01 & .01 & -.03 & $\begin{array}{l}3.12 \\
(1.22)\end{array}$ \\
\hline $\mathrm{r}_{\mathrm{ECCB} . \mathrm{M} 1}$ & -- & -.04 & -.10 & -.10 & .01 & .27 & -- & -- \\
\hline $\mathrm{r}_{\text {ECCB.M2 }}$ & -- & -.01 & -.10 & .13 & -.01 & .26 & -- & -- \\
\hline \multicolumn{9}{|c|}{$\begin{array}{l}* * p<.01 \text { level two-tailed, } * p<.05 \text { level two-tailed. The diagonal shows mean } \\
\text { values, and standard deviations in parenthesis. ECCB = Ecologically Conscious } \\
\text { Consumption Behaviour, Extra = Extraversion, Agree = Agreeableness, Cons }= \\
\text { Conscientiousness, ES = Emotional Stability, OE = Openness to Experience, } \mathrm{r}_{\mathrm{ECCB} . \mathrm{M} 1} \\
=\text { partial correlations between ECCB and other constructs controlling for Marker } 1 \\
\text { variable, } \mathrm{r}_{\mathrm{ECCB} . \mathrm{M} 2=\text { partial correlations between ECCB and other constructs controlling }} \\
\text { for Marker2 variable. }\end{array}$} \\
\hline
\end{tabular}


Table 2 Ecologically conscious consumption behaviour scale items

Scale indicators

Latent Std

construct loadings

To save energy, I drive my car as little as possible.

$\leftarrow$ ECCB $\quad 0.36^{* *}$

I normally make a conscious effort to limit my use of products that are made of or use scarce resources.

$\leftarrow \operatorname{ECCB} \quad 0.80^{* * *}$

When there is a choice, I always choose that product which contributes the least amount of pollution.

$\leftarrow$ ECCB $\quad 0.82 * *$

If I understand the potential damage to the environment that some products can cause, I do not purchase these products.

I have switched products for ecological reasons.

$\leftarrow$ ECCB

I have purchased a household appliance because it uses less electricity than other brands.

$\leftarrow$ ECCB $\quad 0.54 * *$

I have convinced members of my family or friends not to buy some products which are harmful to the $\leftarrow$ ECCB $\quad$ 0.73** environment.

I have purchased products because they cause less pollution.

$\leftarrow$ ECCB $0.92 * *$

When I have a choice between two equal products, I always purchase the one which is less harmful to other people and the environment.

$\leftarrow \operatorname{ECCB} \quad 0.85^{* *}$

I will not buy a product if the company that sells it is ecologically irresponsible.

$\leftarrow$ ECCB $\quad 0.66 * *$

Std Loadings = Standardised loadings; $* *$ Significant at $p .01 ; \mathrm{ECCB}=$ Ecologically Conscious Consumption Behaviour 
Table 3 Hierarchical regression models explaining green behaviour

\begin{tabular}{|c|c|c|c|c|c|c|c|}
\hline $\begin{array}{c}\text { Independent } \\
\text { variables }\end{array}$ & $\beta$ & t-value & $R$ & $\mathrm{R}^{2}$ & $\Delta \mathrm{R}^{2}$ & $F$ & $\begin{array}{c}\text { Significance } \\
\text { of } F\end{array}$ \\
\hline Model 1 & & & .330 & .11 & .11 & 2.983 & .004 \\
\hline Extra & $-.145^{*}$ & -2.008 & & & & & \\
\hline Agree & -.086 & -1.165 & & & & & \\
\hline Cons & .086 & 1.145 & & & & & \\
\hline ES & -.067 & -.878 & & & & & \\
\hline $\mathrm{OE}$ & $.300 * *$ & 4.069 & & & & & \\
\hline Gender_D & .007 & .095 & & & & & \\
\hline MatureOld_D & .023 & .318 & & & & & \\
\hline OldOlder_D̄ & .100 & 1.410 & & & & & \\
\hline \multicolumn{8}{|l|}{ Model 2} \\
\hline Extra & $-.142 *$ & -1.953 & .341 & .12 & .01 & 2.556 & .006 \\
\hline Agree & -.071 & -.942 & & & & & \\
\hline Cons & .080 & 1.063 & & & & & \\
\hline $\mathrm{ES}$ & -.074 & -.951 & & & & & \\
\hline $\mathrm{OE}$ & $.310 * *$ & 4.142 & & & & & \\
\hline Gender_D & .023 & .326 & & & & & \\
\hline MatureOld_D & .023 & .312 & & & & & \\
\hline OldOlder_D & .102 & 1.439 & & & & & \\
\hline M1 & .057 & .807 & & & & & \\
\hline M2 & .074 & 1.058 & & & & & \\
\hline
\end{tabular}

Dependent variable ECCB $=$ Ecologically Conscious Consumption Behaviour. ${ }^{*} p<$ $.05, * * p<.01, \beta=$ standardised regression coefficient, NS = not significant, Extra $=$ Extraversion, Agree $=$ Agreeableness, Cons $=$ Conscientiousness, ES $=$ Emotional Stability, OE = Openness to New Experiences, Gender_D = gender dummy variable having male as the reference category, MatureOld_D = age dummy variable for the mature old group having the young old group as the reference category, OldOlder_D $=$ age dummy variable for the old older group having the young old group as the reference category, $\mathrm{M} 1$ = first marker variable capturing method bias, $\mathrm{M} 2=$ second marker variable capturing acquiescence bias. 